\title{
Social inequalities in health by individual and household measures of social position in a cohort of healthy people
}

\author{
T Chandola, M Bartley, R Wiggins, P Schofield
}

J Epidemiol Community Health 2003;57:56-62

See end of article for authors' affiliations

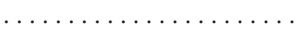

Correspondence to: Dr T Chandola, Department of Epidemiology and Public Health, University College London, 1-19 Torrington Place, London WC1E 6BT, UK; tarani@public-health.ucl.ac.uk

Accepted for publication 13 February 2002

\begin{abstract}
Study objective: It is increasingly recognised that different dimensions of social inequality may be linked to health by different pathways. Furthermore, factors operating at the individual level such as employment conditions may affect health in a different way from household level factors. The paper examines the associations between self rated health and four measures of social positionoccupational class, household social advantage, personal and household income.

Design: Multilevel logistic regression models were used to predict self rated health using longitudinal data from the British Household panel survey (BHPS) with respondents nested within households. Separate analyses were carried out for economically active and inactive respondents.

Setting: Interview based surveys of adults living within households that are representative of British households.

Participants: Adult respondents from the BHPS.

Main results: Occupational class has relatively strong effects on the self rated health of the economically active, although household level factors also seem to influence their health. Household social advantage has relatively strong effects on the self rated health of the economically inactive.

Conclusions: The paper found evidence in support of the view that different dimensions of social inequality have different pathways to self rated health. There are unexplained similarities in health between household members, which require further investigation.
\end{abstract}

$\square$ here is a wealth of evidence linking socioeconomic position and circumstances to health. However, there has been considerable debate about the explanations and underlying causal mechanisms of social inequalities in health. While the literature has moved on from earlier concerns about the relative importance of factors related to health selection, healthy behaviours and material conditions, ${ }^{1-3}$ more recently, there has been considerable research interest into specific pathways from social position to health. These intervening pathways include employment conditions, ${ }^{4}$ household conditions, ${ }^{5}$ and local area conditions. ${ }^{6}$ Disentangling these related but distinct factors could clarify the causal narratives linking social factors to health.

One of the ways of clarifying the underlying mechanisms of social inequalities in health is the use of more specific and better defined measures of social position. Different dimensions of social position may have different underlying causal mechanisms linking social position to health. Sacker et al ${ }^{7}$ found that different dimensions of social position had distinct pathways to health. The Erikson-Goldthorpe class schema (a precursor to the new UK National Statistics Socio-Economic Class schema ${ }^{8}$ ) that measures differences in employment conditions, had strong associations with job strain. In comparison, the Cambridge scale, ${ }^{9}$ which measures household social advantage and lifestyle, had strong associations with smoking behaviour and social support. Furthermore, the EriksonGoldthorpe class schema had stronger associations with the health of women in full time employment, while the Cambridge scale had stronger associations with the health of full time family workers. Chandola ${ }^{10}$ also found that the Cambridge scale had stronger associations with healthy lifestyle behaviours compared with the Erikson-Goldthorpe class schema.

Both the Cambridge scale and the Erikson-Goldthorpe class schema (and the new National Statistics Socio-Economic Class schema) are occupationally based measures. There has been some debate over which socioeconomic indicators such as occupational class, education, or income have stronger associations with health. ${ }^{11}$ Rose and Pevalin ${ }^{12}$ argue that occupational class is of primary importance in understanding how the social structure affects both income and health and their position is empirically supported by Dahl. ${ }^{11}$ On the other hand, other studies have reported income as having stronger associations with health compared with occupational class. $^{1314}$ Furthermore, the effects of personal income on health may be different from household level income. While household income may be a better measure of material resources and physical living conditions, personal income may affect health through different pathways such as decision lattitude, feeling of control, and self esteem. ${ }^{\prime \prime}$

Although education has a powerful relation with social class, status, and income in adulthood, it is not itself a measure of position in the social structure or of adult socioeconomic circumstances. Studies from the $\mathrm{UK}^{15}$ and Norway ${ }^{11}$ show that occupational social class is a stronger predictor of health outcomes than education. Furthermore, there is evidence that social inequalities in health are greatest when using current socioeconomic position, at least in the $\mathrm{UK}^{16}$ suggesting that the mechanisms underlying social inequalities in health may be related more strongly to current social circumstances rather than childhood circumstances.

These studies indicate that further research into the association between health and measures of social position at the individual and household level needs to be carried out. The mechanisms underlying the association between health and individual occupational class and personal income may be different from the mechanisms involving household social advantage and household income. If household level factors have an important effect on health, over and above individual demographic and socioeconomic characteristics, then these factors need to be explicitly measured and taken into account in a multilevel analysis. Multilevel analysis explicitly recognises the hierarchical structure of our data source ${ }^{17} 18$ and allows us to examine the relative impact of these factors at 
each level. To date, to the best of the authors' knowledge, there have not been any such analyses of social inequalities in health that have used the household as an explanatory level.

Furthermore, as Sacker et al found, there may be different pathways to health between people who are economically active and inactive. It may be important to analyse these groups separately to clarify the underlying mechanisms that generate social inequalities in health. Factors related to employment conditions such as job stress and job insecurity are likely to be of more importance in understanding health inequalities among economically active people, while factors related to household circumstances and income may be of greater importance in understanding health inequalities among economically inactive people.

This paper investigates the association between four measures of social position-occupational social class, household social advantage, personal income, and household income-in relation to health status in the economically active and inactive population. In particular, the paper examines the question whether household measures of social position are independently associated with health status after controlling for individual measures of social position.

\section{METHODS \\ Data}

The British Household Panel Survey (BHPS) is a longitudinal cohort survey of adult members of a nationally representative sample of British households (5511 households with 10264 adult members). The initial survey was conducted in 1991 and subsequent annual surveys for the cohort were added to the original data. The latest wave of the BHPS for which there were available data at the time this paper was written was in 1998. Further information on the methodology of the survey can be found in Taylor et al. ${ }^{19}$

\section{Variables}

\section{Self rated health}

Respondents were asked to rank their health on a five point scale from excellent to very poor compared with others of their own age, over the past 12 months. This was grouped into a binary variable of good (excellent to good) and poor (fair to very poor) self rated health. Data on self rated health from the first eight waves of the BHPS were collected although only information from the first and eighth waves were used in the analysis to avoid the complexity of changes in household composition between waves.

\section{Age}

Age was coded into seven age groups- 18-24 years, 25 to 34, 35 to 44,45 to 54,55 to 64,65 to 74 , and 75 years and above.

\section{Employment status}

Respondents were categorised into those in full time employment (30 hours or more a week), part time employment, the unemployed, full time family workers, the retired, and those with long term illnesses or disabilities. Those in full time employment, part time employment, and the unemployed were categorised as economically active. The small number of full time students, those on maternity leave, and government training schemes were also classified as being economically active. Full time family workers, the retired, and the long term disabled were categorised as economically inactive. Only information from wave 1 of the BHPS was used for this variable.

\section{Measures of social position}

All the measures of social position used information only from wave 1 of the BHPS.

Respondents were assigned a social class within the National Statistics Socio-Economic Classification (NS-SEC) on the basis of their most recent occupation thus enabling currently economically inactive respondents to be classified by their last occupation. Among the economically active, around $5 \%$ of the respondents could not be assigned a social class (probably because of missing or incomplete occupational data). Among the economically inactive, around $14 \%$ of the respondents could not be assigned a social class (probably because of missing or incomplete occupational data as well as respondents who had never worked such as some women who are full time family workers). The five class version of the NS-SEC was used in preference to the seven class version to reduce the number of categories containing small numbers in the analysis.

The Cambridge scale, another occupational classification, is a hierarchical measure of "stratification arrangements that involve differences in generalised advantage". ${ }^{9}$ Differences in general social advantage are reflected by the social distance between occupations-social distance being defined by similarities in lifestyles and resources ${ }^{20}$ Respondents were assigned a Cambridge scale score on the basis of the highest Cambridge scale score of members in their household. ${ }^{5}$ These scores were categorised into quintiles.

Personal income was derived from the respondent's annual labour and non-labour income and derived by the BHPS data team. Household income was also derived by the BHPS data team and equivalised for household size using the McClements scale. A more comprehensive measure of household income in the BHPS has been calculated by Jenkins et $a l^{21}$ from derived net income variables at the household level. However, because of the comparatively large numbers of missing values, the Jenkins measure of household income in the BHPS data was not used in this analysis.

\section{Analysis}

Only adult (aged 18 and over) respondents in the BHPS who had excellent or good self rated health at the first wave of the BHPS were analysed for the multilevel models. This method reduces the possibility of health selection (people with initially poor health end up in lower and more disadvantaged social positions) as the analysis is carried out on an initially healthy cohort-this potentially reduces the pathways to inequalities in health. These healthy adult respondents were separated in two groups-those who were economically active (those in employment, unemployed, full time students, on maternity leave, or on a government training scheme) at wave 1 and those who were economically inactive (those who had retired, were family carers or long term sick/disabled) at wave 1.

Multilevel logistic models ${ }^{17}$ were used to analyse the association between the binary health variable self rated health with a number measures of social position adjusted for age, sex, and employment status. Multilevel models were chosen in preference to ordinary logistic regression analysis as such models make explicit use of the hierarchical or clustered nature of the BHPS sample-individuals are nested within households. Multilevel models provide the appropriate estimates of standard errors that allow for the clustering of individuals within households. This produces regression coefficient estimates, such as measures of household social position that properly account for any lack of independence at the individual level. Typically, in any multilevel analysis ${ }^{22}$ the effects of clustering are captured by a summary statistic, the intraclass correlation $(\rho)$ that estimates the extent to which the health of members of the same household are similar as compared with members of different households. Put another way, it measures the proportion of the total variance accounted for by differences between households. In multilevel logistic regression models, $\rho$ (the intraclass correlation) can be estimated as the level 2 variance divided by (the level 2 variance $+\Pi^{2} / 3$ ) following Hedeker and Mermelstein. ${ }^{23}$ For further discussion on this matter see Goldstein et al. ${ }^{22}$ 
Table 1 Self rated health at waves 1 and 8 and household size (wave 1) by economic activity status (wave 1)-unweighted and weighted percentage of BHPS respondents

\begin{tabular}{|c|c|c|c|c|}
\hline & \multicolumn{2}{|c|}{ Economically active at wave 1} & \multicolumn{2}{|c|}{ Economically inactive at wave 1} \\
\hline & Unweighted & Weighted & Unweighted & Weighted \\
\hline \multicolumn{5}{|c|}{ Self rated health at wave 1} \\
\hline Good & 80.9 & 81.3 & 59.0 & 64.0 \\
\hline Poor & 19.1 & 18.7 & 40.9 & 36.0 \\
\hline Missing & 0.0 & 0.0 & 0.1 & 0.1 \\
\hline Total number & 6004 & 3613 & 2726 & 1689 \\
\hline \multicolumn{5}{|c|}{ Self rated health at wave 8} \\
\hline Good & 54.4 & 73.3 & 32.8 & 52.0 \\
\hline Poor & 19.0 & 26.6 & 28.3 & 47.9 \\
\hline Missing & 26.7 & 0.1 & 38.9 & 0.1 \\
\hline Total number & 6004 & 3613 & 2726 & 1689 \\
\hline \multicolumn{5}{|c|}{ Household size (number of household members) at wave 1} \\
\hline 1 & 16.0 & 13.7 & 37.8 & 36.7 \\
\hline 2 & 57.4 & 56.4 & 52.8 & 53.3 \\
\hline 3 & 17.5 & 18.5 & 7.3 & 7.8 \\
\hline 4 & 7.4 & 8.5 & 1.9 & 2.0 \\
\hline 5 & 1.6 & 2.7 & 0.3 & 0.2 \\
\hline 6 or more & 0.1 & 0.2 & 0.0 & 0.1 \\
\hline Total number & 6004 & 3613 & 2726 & 1689 \\
\hline
\end{tabular}

The modelling strategy adopted was to analyse, at first, separate models of self rated health with the different measures of social position, adjusted for age, sex, and economic activity status. This enables us to see the basic associations between the different measures of social position and self rated health. Then, all the four measures of social position were entered into the same model. If the odds ratio associated with a measure of social position does not change greatly, and if the measure's overall effect significantly reduces the likelihood, this suggests that there is an effect of that measure on self rated health independently of the other dimensions of social position. Such a model enables us to determine the relative strength of the causal pathways involving the different dimensions of social position (such as individual versus household effects of income).

Longitudinal weights were applied to the analysis to allow for sample loss between waves of the BHPS. Data on around $35 \%$ of the original respondents at wave 1 could not be collected by wave 8 , so longitudinal weights have been designed to make the remaining respondents at wave 8 representative of the population. These individual level weights were calculated by the BHPS data team. ${ }^{19}$ For multilevel analysis, the household level weights at wave 8 were used, which have also been calculated by the BHPS team. ${ }^{19}$

\section{RESULTS}

There were 8730 (unweighted) respondents in the first wave of the BHPS for whom there was complete information on their employment status, household and personal income, NS-SEC class, and household Cambridge scale scores. The distribution of these respondents by self rated health and household size among economically active and economically inactive respondents are shown in table 1 .

Among the economically active respondents, $19 \%$ had poor self rated health while $81 \%$ had good self rated health at wave 1. By wave 8 , information on $26.7 \%$ of these economically active respondents was not available mainly because of attrition from the cohort sample. As the longitudinal weights have been calculated only for those respondents remaining in the sample at wave 8 , much of the reduction in the unweighted (6004) to weighted (3613) sample sizes is mainly attributable to respondents missing at wave 8 . The implications for this reduction in sample size is discussed in the caveats section of the discussion.
Among the economically inactive respondents, $41 \%$ had poor self rated health at wave 1 . This is much higher than the prevalence of poor health in the economically active respondents, which is not surprising given that the economically inactive contain the elderly retired population as well as people with disabilities who cannot work. By wave 8 , information on around $39 \%$ of the economically inactive cohort was not available. Once again, the reduction in the unweighted (2726) to weighted (1689) sample sizes is mainly attributable to these missing respondents at wave 8 .

Sixteen per cent of (unweighted) economically active respondents lived in single person households at wave 1 . In comparison, the percentage of (unweighted) economically inactive respondents living in single person households at wave 1 was nearly three times higher $(38 \%)$. Weighting did not substantially change these percentages.

Table 2 presents the results of the multilevel logistic regression analyses for the economically active respondents. Only the odds (and 95\% confidence intervals) of poor self rated health for the measures of social position are reported in the table for clarity. Increasing age is associated with poorer self rated health (analysis not shown). In general, women have poorer self rated health compared with men although this difference in health between genders was not statistically significant in all the models (analysis not shown). Respondents who were in part time employment at wave 1 had poorer health than those in full time employment (analysis not shown). This effect seems to be independent of gender although around $80 \%$ of part time workers are women. The unemployed had the poorest self rated health among all economically active respondents in all the models.

The NS-SEC is significantly associated with poor self rated health-respondents who are in the working classes are 1.7 times more likely to have poor health compared with respondents who are in the managerial and professional classes (Model I, table 2). When adjusted for the other measures of social position (Model V, table 2), the odds ratios are moderately reduced and the overall association of the NS-SEC to self rated health is on the margin of statistical significance. Furthermore, in Model V, respondents in the supervisor/craft and the working classes have significantly poorer health than managerial and professional respondents.

Respondents in the lowest Cambridge quintile (or in other words in households with the least social advantage) had significantly poorer self rated health compared with respondents in households with the greatest social advantage (Model II, 
Table 2 Odds ratios (and 95\% confidence intervals) of poor self rated health at wave 8 of the BHPS. Multilevel logistic regression with measures of social position adjusted for age, sex, and employment status. Economically active respondents at wave 1 of the BHPS. Longitudinal weights applied at the individual level and household weights at the household level

\begin{tabular}{|c|c|c|c|c|c|c|}
\hline Variables & Model I & Model II & Model III & Model IV & Model V & $\mathrm{N}$ \\
\hline \multicolumn{7}{|c|}{ Age + Sex + Employment Status (wave 1) + } \\
\hline Managerial and Professional ${ }^{*}$ & 1.00 & & & & 1.00 & 1073 \\
\hline Intermediate & $1.3(1.0$ to 1.8$)$ & & & & $1.1(0.8$ to 1.6$)$ & 528 \\
\hline Small employers & 1.5 (1.0 to 2.1$)$ & & & & $1.4(1.0$ to 2.1$)$ & 304 \\
\hline Supervisors and Craft & 1.7 (1.2 to 2.3$)$ & & & & $1.6(1.1$ to 2.3$)$ & 351 \\
\hline Working class & 1.7 (1.3 to 2.3$)$ & & & & 1.5 (1.1 to 2.2$)$ & 885 \\
\hline p on $4 \mathrm{df} \dagger$ & 0.00 & & & & 0.06 & \\
\hline \multicolumn{7}{|c|}{ Cambridge scale (quintiles) (wave 1) } \\
\hline 1 High social advantage* & & 1.0 & & & 1.0 & 639 \\
\hline 2 & & $1.2(0.8$ to 1.7$)$ & & & $1.1(0.8$ to 1.6$)$ & 619 \\
\hline 3 & & $1.4(1.0$ to 1.9$)$ & & & $1.1(0.8$ to 1.6$)$ & 623 \\
\hline 4 & & $1.3(0.9$ to 1.8$)$ & & & $0.9(0.6$ to 1.3$)$ & 634 \\
\hline 5 Low social advantage & & 1.7 (1.2 to 2.3$)$ & & & $1.1(0.7$ to 1.6$)$ & 626 \\
\hline $\mathrm{p}$ on $4 \mathrm{df} \dagger$ & & 0.08 & & & 0.58 & \\
\hline \multicolumn{7}{|l|}{ Personal income (wave 1) } \\
\hline 1 Highest income quintile* & & & 1.0 & & 1.0 & 628 \\
\hline 2 & & & $1.2(0.9$ to 1.7$)$ & & $1.1(0.8$ to 1.6$)$ & 628 \\
\hline 3 & & & 1.6 (1.2 to 2.3$)$ & & $1.4(1.0$ to 2.1$)$ & 629 \\
\hline 4 & & & 1.7 (1.2 to 2.5$)$ & & $1.4(1.0$ to 2.1$)$ & 628 \\
\hline 5 Lowest income quintile & & & $1.5(1.0$ to 2.2$)$ & & $1.2(0.8$ to 1.8$)$ & 628 \\
\hline p on $4 \mathrm{df} \dagger$ & & & 0.01 & & 0.22 & \\
\hline \multicolumn{7}{|l|}{ Household income (wave 1) } \\
\hline 1 Highest income quintile* & & & & 1.0 & 1.0 & 627 \\
\hline 2 & & & & $1.1(0.8$ to 1.6$)$ & 1.1 (0.8 to 1.5$)$ & 630 \\
\hline 3 & & & & $1.1(0.8$ to 1.6$)$ & $1.0(0.7$ to 1.5$)$ & 627 \\
\hline 4 & & & & $1.1(0.8$ to 1.6$)$ & $0.9(0.6$ to 1.3$)$ & 629 \\
\hline 5 Lowest income quintile & & & & $1.5(1.1$ to 2.1$)$ & $1.3(0.9$ to 1.9$)$ & 628 \\
\hline $\mathrm{p}$ on $4 \mathrm{df} \dagger$ & & & & 0.12 & 0.24 & \\
\hline $\begin{array}{l}\text { Variance at household level (and } \\
\text { standard error) }\end{array}$ & $0.76(0.17)$ & $0.82(0.17)$ & $0.85(0.18)$ & $0.76(0.17)$ & $0.80(0.17)$ & \\
\hline Variance at individual level & 1.00 & 1.00 & 1.00 & 1.00 & 1.00 & \\
\hline Intra class correlation & 0.19 & 0.20 & 0.21 & 0.19 & 0.20 & \\
\hline
\end{tabular}

table 2). However, the odds ratios are considerably reduced when the other measures of social position were adjusted for (Model V, table 2) and the association between the Cambridge quintiles and self rated health is no longer statistically significant.

In general, decreasing personal income is associated with poorer self rated health although this linear effect is curtailed in the lowest income quintile (Model III, table 2). However, the association between the personal income and self rated health is non-significant when adjusted for the other measures of social position (Model V, table 2).

Respondents in the lowest household income quintile have significantly poorer heath compared with respondents in the highest household income quintile (Model IV, table 2). However, this association reduces to non-significance when adjusted for the other measures of social position (Model V, table 2 ).

In all the models in table 2, the variance associated with the household level is significantly different from zero-the estimates for the variance is over twice its standard error. This indicates that there are significant similarities in self rated health within households even after adjusting for a number of individual and household level socioeconomic and demographic factors (Model V). The intraclass correlation is around $20 \%$ indicating that $20 \%$ of the total variance in self rated health can be identified at the household level.

Next, we consider the findings for the economically inactive respondents. Once again, only the odds (and 95\% confidence intervals) of poor self rated health for the measures of social position are reported in the table for clarity. Among the economically inactive, increasing age is associated with poorer health (analysis not shown). As in table 2, there are no statis- tically significant differences in self rated health between genders (analysis not shown). Respondents with long term illnesses or disabilities have the highest estimated odds of poor self rated health (analysis not shown) although the overall association between employment status and self rated health is not significant.

Among economically inactive respondents, the NS-SEC (assigned on their last held occupation) is significantly associated with poor self rated health-respondents in the working classes are 1.7 times more likely to have poor health compared with respondents in the managerial and professional classes (Model I, table 3). The high estimated odds of poor self rated health for the small employer class may be an artefact of the comparatively small numbers in this class. When adjusted for the other measures of social position, the NS-SEC is not significantly associated with self rated health (Model V, table 3).

Decreasing household social advantage as measured by the Cambridge scale is associated with poorer self rated health (Model II, table 3). When adjusted for the other measures of social position (Model V, table 3), the odds ratios for the Cambridge quintiles remain unchanged and the linear association between the Cambridge scale and self rated health is still very evident.

Personal income is associated with self rated health among the economically inactive. However, this is not a linear association as the group with the poorest self rated health is the second highest income quintile. This association may arise from the concentration of people on disability related benefits in this income quintile. In comparison with the other models, the odds of poor self rated health for long term sick and disabled respondents are reduced in this model (analysis not shown), suggesting that this association between personal 
Table 3 Odds ratios (and 95\% confidence intervals) of poor self rated health at wave 8 of the BHPS. Multilevel logistic regression with measures of social position adjusted for age, sex, and employment status. Economically inactive respondents at wave 1 of the BHPS. Longitudinal weights applied at the individual and household levels

\begin{tabular}{|c|c|c|c|c|c|c|}
\hline Variables & Model I & Model II & Model III & Model IV & Model V & $\mathrm{N}$ \\
\hline \multicolumn{7}{|c|}{$\begin{array}{l}\text { Age }+ \text { Sex }+ \text { Employment Status (wave 1) + } \\
\text { NS-SEC (wave 1) }\end{array}$} \\
\hline Managerial and Professional ${ }^{*}$ & 1.00 & & & & 1.00 & 247 \\
\hline Intermediate & $0.9(0.6$ to 1.4$)$ & & & & 0.7 (0.4 to 1.1$)$ & 192 \\
\hline Small employers & 1.9 (1.0 to 3.6$)$ & & & & $1.3(0.7$ to 2.6$)$ & 56 \\
\hline Supervisors and Craft & $1.1 \quad(0.7$ to 1.9$)$ & & & & $0.6(0.4$ to 1.2$)$ & 105 \\
\hline Working class & $1.7(1.1$ to 2.4$)$ & & & & $1.0(0.6$ to 1.6$)$ & 365 \\
\hline $\mathrm{p}$ on $4 \mathrm{df} \dagger$ & 0.00 & & & & 0.13 & \\
\hline \multicolumn{7}{|c|}{ Cambridge scale (quintiles) (wave 1) } \\
\hline 1 High social advantage* & & 1.0 & & & 1.0 & 193 \\
\hline 2 & & $1.1(0.7$ to 1.7$)$ & & & $1.1(0.6$ to 1.8$)$ & 191 \\
\hline 3 & & 1.6 (1.0 to 2.5 ) & & & $1.6(0.9$ to 2.7$)$ & 198 \\
\hline 4 & & 1.8 (1.1 to 2.9$)$ & & & 1.8 (1.0 to 3.2$)$ & 191 \\
\hline 5 Low social advantage & & $2.3(1.4$ to 3.6$)$ & & & $2.2(1.2$ to 3.9$)$ & 192 \\
\hline $\mathrm{p}$ on $4 \mathrm{df} \dagger$ & & 0.00 & & & 0.04 & \\
\hline \multicolumn{7}{|l|}{ Personal income (wave 1) } \\
\hline 1 Highest income quintile* & & & 1.0 & & 1.0 & 193 \\
\hline 2 & & & $2.3(1.5$ to 3.6$)$ & & 1.9 (1.1 to 3.1$)$ & 193 \\
\hline 3 & & & $1.5(0.9$ to 2.4$)$ & & $1.1 \quad(0.6$ to 1.8$)$ & 193 \\
\hline 4 & & & 1.5 (0.9 to 2.4$)$ & & $1.2(0.7$ to 2.0$)$ & 193 \\
\hline 5 Lowest income quintile & & & $1.1(0.6$ to 2.0$)$ & & $0.9(0.5$ to 1.7$)$ & 193 \\
\hline $\mathrm{p}$ on $4 \mathrm{df} \dagger$ & & & 0.00 & & 0.03 & \\
\hline \multicolumn{7}{|l|}{ Household income (wave 1) } \\
\hline 1 Highest income quintile* & & & & 1.0 & 1.0 & 193 \\
\hline 2 & & & & 0.7 (0.4 to 1.1$)$ & $0.6(0.4$ to 1.1$)$ & 192 \\
\hline 3 & & & & 0.8 (0.5 to 1.3 ) & $0.6(0.4$ to 1.1$)$ & 194 \\
\hline 4 & & & & 0.9 (0.6 to 1.5$)$ & 0.7 (0.4 to 1.2$)$ & 193 \\
\hline 5 Lowest income quintile & & & & 1.4 (0.9 to 2.2$)$ & $1.0(0.6$ to 1.7$)$ & 193 \\
\hline $\mathrm{p}$ on $4 \mathrm{df} \dagger$ & & & & 0.03 & 0.14 & \\
\hline $\begin{array}{l}\text { Variance at household level (and } \\
\text { standard error) }\end{array}$ & $0.15(0.21)$ & $0.15(0.21)$ & $0.12(0.21)$ & $0.14(0.21)$ & $0.19(0.22)$ & \\
\hline Variance at individual level & 1.00 & 1.00 & 1.00 & 1.00 & 1.00 & \\
\hline Intra class correlation & 0.04 & 0.04 & 0.04 & 0.04 & 0.05 & \\
\hline
\end{tabular}

income and self rated health among the economically inactive reflects the health of disabled respondents to some extent. As disability payments contribute towards personal income, disabled respondents may not be the poorest among the economically inactive in terms of their personal income. Even when adjusted for the other measures of social position (Model V, table 3), the second highest income quintile has significantly poorer self rated health compared with the highest income quintile. In contrast, the odds of poor self rated health among the lowest income quintile are not different from the highest income quintile. This suggests that the effect of personal income on self rated health among the economically inactive may reflect disability status more so than an effect of the social structure on health.

Household income is significantly associated with self rated health among the economically inactive (Model IV, table 3), although this seems to be a "J" shaped association rather than a linear one. However, when adjusted for the other measures of social position (Model V, table 3), this association is no longer significant.

In all the models in table 3, the variance associated with the household level is not significantly different from zero indicating that there are no significant similarities in self rated health between members of the economically inactive households. This may be attributable to the comparatively greater proportion of single person economically inactive households, which reduces the likelihood of distinct household level effects separate from individual level effects. Economically inactive respondents are nearly three times more likely to live in single person households compared with economically active respondents (as shown in table 1). The comparatively large proportion of economically inactive single person households may also explain the low intraclass correlation.
Interaction effects between all the variables in the above models were examined and found to be non-significant. In particular, the interactions between gender and employment status and between gender and the measures of social position were not significantly associated with self rated health.

\section{DISCUSSION}

The results show that among an initially healthy cohort of economically active respondents, the strongest predictor of self rated health among different measures of social position is the NS-SEC. In contrast, among an initially healthy cohort of economically inactive respondents, the strongest predictor of self rated health among different measures of social position is the respondents' household Cambridge scale score. These results support the view that different dimensions of social position may have different underlying causal mechanisms linking them to health outcomes and also support the findings of Sackeret al and Dahl. ${ }^{11}$

The NS-SEC has been explicitly theorised to represent differences in employment relations and conditions. A number of studies have shown that employment related factors such as physical working conditions, job insecurity, job control, and psychosocial support by colleagues ${ }^{24} 25$ are associated with health. The strong association of the NS-SEC with self rated health among the economically active could be attributable to the differential distribution of such employment related factors among the social classes distinguished by this measure. Furthermore, among the economically active, household social advantage, personal income, and household income were not as strongly related to self rated health as the NS-SEC. This may indicate that the underlying mechanisms of social inequality in health among the economically active may 


\section{Key points}

- Different dimensions of social position have different path ways to health

- Individual occupational class has comparatively strong effects on the self rated health of the economically active.

- Household social advantage has comparatively strong effects on the self rated health of the economically inactive.

be more directly related to occupational factors rather than household social advantage or material resources.

However, the results for economically active respondents also showed that the household level variance in self rated health was significant and was not accounted for by the respondent's employment conditions, household social advantage, and personal/household income. Around $20 \%$ of the total variance in the self rated health of the economically active can be attributed to differences between households. This suggests that household level mechanisms may have an effect on individual health, although somewhat paradoxically, these household level mechanisms do not seem to be related to household income or household social advantage. Such household level variation in health may potentially be accounted for by other household factors such as the division of household labour, ${ }^{26}$ domestic conditions, ${ }^{27}$ household social support and networks, ${ }^{28}$ and higher aggregate level factors such as local neighbourhood conditions related to deprivation, social disorganisation, and social capital. ${ }^{6}$ To the best of the authors' knowledge, this paper is the first to directly measure such household level variation in health. The results indicate that further research into similarities in health between household members needs to be carried out. Indeed, the routine use of multilevel analyses is advocated for these data to explore the extent of change at both an individual level (as accounts may vary over time) and at a household level. In theory, it is possible to consider more complex multilevel structures such as multiple membership models that would facilitate the analysis of change at an individual and household level. ${ }^{29}$

The importance of household level factors in influencing health is further underlined by the strength of the household Cambridge scale score in predicting self rated health among economically inactive people. Social class based on previous employment, personal income, and household income were not as strongly associated with self rated health. There is a growing body of evidence on the usefulness of the Cambridge scale in predicting mortality and morbidity. ${ }^{510}$ There is also some evidence that scale is strongly related to health behaviours and social support. ${ }^{10}$ It is possible that as the Cambridge scale is based on friendship and lifestyle dimensions, it represents household factors such as household diet and social support more accurately than other measures of social position. Further research into the specific mechanisms underlying the association between the Cambridge scale and health outcomes is indicated.

Income, whether measured at the personal or household level, did not have as strong an effect on self rated health as the NS-SEC and Cambridge scale. This result may seem surprising given the strong associations reported between income and health or mortality in a number of studies. ${ }^{3031}$ However, most of these studies do not control for economic activity status. Stronks et $a l^{13}$ argue that much of the association between income and health is attributable to the concentration of the long term disabled in lower income groups. As the long term disabled are usually excluded from paid employment, the strong association between income and health may be attributable to health related selection rather than a causal effect of income on health. There is some evidence for this from the increased chances of poor self rated health in the second highest income quintile among the eco- nomically inactive. This income quintile contains the highest proportion of respondents on disability related allowances and so the poor health status in that income quintile may be a result of health selection into that group. It is therefore necessary to control for employment status in any analysis of the causal pathways linking income to health. When employment status was not controlled for (analysis not shown), both personal and household income were significantly associated with self rated health even after adjusting for the other measures of social position.

Employment status had the expected relation to self rated health. Those in part time employment had poorer health compared with those in full time employment. The unemployed had the poorest health among those who were economically active. Among the economically inactive, those with long term illnesses or disabilities had the poorest self rated health although the differences in health between full time home workers, the retired, and the disabled were not statistically significant. The results also showed that it is useful to analyse economically active respondents separately from the economically inactive respondents. It is possible that the effect of the different measures of social position on health may differ between the economically active and inactive population. Among the economically inactive in particular, the comparatively weaker effect of an occupational measure like the NS-SEC on health may not be surprising as it is assigned on the basis of the respondent's previous occupation, which may not be an accurate measure of their current social position. Furthermore, both personal and household income among the economically inactive may not reflect their social position as well as the Cambridge scale, which may reflect more accurately their household social status and wealth.

The paper did not find any significant gender differences in self rated health nor were there any significant interactions between gender and employment status, or between gender and the different measures of social position. This supports results from recent studies ${ }^{32}{ }^{33}$ that challenge the view that women report greater morbidity and poorer self rated health compared with men.

One of the caveats of this paper, which is common to all longitudinal cohort studies, is the problem of sample loss. Respondents may not be available across all waves of the study. It is therefore possible that the social position of non-respondents and respondents at wave 8 of the BHPS may differ and this in turn may affect our findings. While the longitudinal weights used in the analysis are designed to make the remaining respondents at wave 8 representative of the adult British population, ${ }^{19}$ these weights may not solve the problem of the differential selection of certain social groups out of the cohort by wave 8 . Weighted analyses implicitly assume that respondents who belong to the subgroups defined by the weights are themselves a random sample of all potential members of those subgroups (non-responders and responders alike). To examine the effect of such selection biases on the results of this paper, further regression analyses were undertaken to examine whether respondents from certain social groups (at wave 1) were more likely to drop out of the cohort by wave 8 (analyses not shown). Elderly respondents and respondents from more disadvantaged social positions were more likely to drop out of the cohort compared with younger and more advantaged respondents respectively. However, none of the measures of social position were significantly associated with dropping out when they were analysed together. This suggests that although there is evidence of some selection bias in the cohort, this bias does not seem to affect the substantive results of the paper. In particular, respondents from low income groups (whether personal income or household income) were not more likely to drop out of the cohort compared with respondents from disadvantaged Cambridge groups or working classes. 
The paper found evidence in support of the view that different dimensions of social position have different pathways to health. Individual occupational class has relatively strong effects on the self rated health of the economically active, although household level factors also contribute towards health. Household social advantage has strong effects on the self rated health of the economically inactive. Further research into the similarities in health between household members is indicated.

\section{ACKNOWLEDGEMENTS}

The data and tabulations used in this publication were made available through The ESRC Data Archive. The data were originally collected by the ESRC Research Centre on Micro-Social Change at the University of Essex. Neither the original collectors of the data nor the Archive bear any responsibility for the analyses or interpretations presented here. The authors would also like to thank the journal referees for their comments and suggestions for this paper

\section{Authors' affiliations}

T Chandola, M Bartley, P Schofield, Department of Epidemiology and Public Health, University College London, London, UK

R Wiggins, Department of Sociology, City University, London, UK

Conflicts of interest: there were no conflicts of interest between the funding bodies of the authors and the results and conclusions of the paper.

\section{REFERENCES}

1 Black D, Morris JN, Smith C, et al. Inequalities in health: The Black report; The health divide. London: Penguin Group, 1988.

2 Stern J. Social mobility and the interpretation of social class mortality differentials. Journal of Social Policy 1983;12:27-49.

3 Blaxter M. An assessment of the Black Report's explanations of health inequalities. Sociology of Health and Illness 1985;7:1985.

4 Bosma $\mathrm{H}$, Marmot MG, Hemingway $\mathrm{H}$, et al. Low job control and risk of coronary heart disease in the Whitehall II (prospective cohort) study. BM 1997; 314:558-65.

5 Sacker A, Firth D, Fitzpatrick $R$, et al. Comparing health inequality in men and women: prospective study of mortality 1986-96. BM 2000:320:1303-7

6 Chandola T. The fear of crime and area differences in health. Health and Place 2001;7:105-16.

7 Sacker A, Bartley M, Firth D, et al. Dimensions of social inequality in the health of women in England: occupational, material and behavioural pathways. Soc Sci Med 2001;52:763-81.

8 Rose D, O'Reily K. Constructing classes. Swindon: ESRC/ONS, 1997.

9 Prandy K. The revised Cambridge scale of occupations. Sociology 1990;24:629-55.

10 Chandola T. Social inequality in coronary heart disease: a comparison of occupational classifications. Soc Sci Med 1998;47:525-33.

11 Dahl E. Social inequalities in ill-health: the significance of occupational status, education and income- results from a Norwegian survey. Sociology of Health and Illness 1994;16:644-67.
12 Rose D, Pevalin DJ. Social class differences in mortality using the National Statistics Socio-economic classification - too little, too soon: a reply to Chandola. Soc Sci Mede 2000;7:1 121-7

13 Stronks K, Van de Mheen H, Van den Bos J, et al. The interrelationship between income, health and employment status. Int J Epidemiol 1997;26:592-600.

14 Geyer S, Peter R. Income, occupational position, qualification and health inequalities- competing risks? (Comparing indicators of social status). Journal of Social Policy 2000:54:299-305.

15 Davey Smith G, Hart C, Hole D, et al. Education and occupational social class: which is the more important indicator of mortality risk? J Epidemiol Community Health 1998;52:153-60

16 Harding S, Rosato M, Brown J, et al. Social patterning of health and mortality: children, aged 6-15 years, followed up for 25 years in the ONS Longitudinal Study. Health Statistics Quarterly 1999;3:30-4.

17 Goldstein H. Multilevel statistical models, Kendall's library of statistics 3. London: Edward Arnold, 1995.

18 Kreft I, De Leeuw J. Introducing multilevel modelling. London: Sage, 1998.

19 Taylor M, Brice J, Buck N, et al. British Household Panel Survey user manual. Volume A: Introduction, technical report and appendices. Colchester: University of Essex, 1999.

20 Prandy K, Bottero W. The social analysis of stratification and mobility: working paper no 18. Cambridge: Sociological Research Group, 1995

21 Jenkins SP, Bardasi E, Rigg JA. British Household Panel Survey derived current and annual net household income variables waves 1-7, 1991-1998 [computer file]. 2nd edn. Colchester: Economic and Social Research Council Research Centre on Micro-Social Change, 1999. [original data producer]

22 Goldstein H, Browne W, Rabash J. Extensions of the intra-unit correlation coefficient to complex generalised linear multilevel models. London: Multilevel Models Project, Institute of Education. (http://multilevel.ioe.ac.uk/team/icccglmm.pdf).

23 Hedeker D, Mermelstein RJ. Application of random-effects regression models in relapse research. Addiction 1996;91 (suppl):S211-29.

24 Stansfeld SA, Fuhrer R, Head J, et al. Work and psychiatric disorder in the Whitehall II study. J Psychosom Res 1997;43:73-81.

25 Schrijvers CT, Van de Mheen $\mathrm{H}$, Stronks K, et al. Socioeconomic inequalities in health in the working population: the contribution of working conditions. Int J Epidemiol 1998;27:1011-18.

26 Glass J, Fujimoto T. Housework, paid work, and depression among husbands and wives. J Health Soc Behav 1994;35:179-91.

27 Bartley M, Popay J, Plewis I. Domestic conditions, paid employment and women's experience of ill-health. Sociology of Health and Illness 1992; 14:313-43

28 Ross CE, Mirowsky J, Huber J. Dividing work, sharing work, and in-between: marriage patterns and depression. American Sociological Review 1983;48:809-23.

29 Goldstein H, Rasbash J, Browne W, et al. Multilevel models in the study of dynamic hosuehold structures. European Journal of Population 2000;16:373-87

30 Blaxter M. Health and lifestyles. London: Tavistock/Routledge, 1990.

31 Winkleby MA, Jatulis DE, Frank E, et al. Socioeconomic status and health: how education, income, and occupation contribute to risk factors for cardiovascular disease. Am J Public Health 1992;82:816-20.

32 Arber S, Cooper H. Gender differences in health in later life: the new paradox? Soc Sci Med 1999:48:61-76.

33 Emslie C, Hunt K, Macintyre S. Problematizing gender, work and health: the relationship between gender, occupational grade, working conditions and minor morbidity in full-time bank employees. Soc Sci Med 1999:48:465-75. 